\title{
Leisure Pilot License Proposed for Europe: Do You Want Such Pilots Crossing Your Flight Path?
}

\author{
Ries Simons, Declan Maher, Uwe Stüben, \\ and Kevin C. Herbert
}

\begin{abstract}
Simons R, MAHer D, STÜBen U, Herbert KC. Leisure pilot license proposed for Europe: do you want such pilots crossing your flight path? Aviat Space Environ Med 2009; 80:663-4.

In a Notice of Proposed Amendment, the European Aviation Safety Agency proposes to introduce a Leisure Pilot License (LPL). Holders of a LPL for airplanes will be allowed to fly single-engine piston airplanes with a maximum takeoff mass of $2000 \mathrm{~kg}$ or less, carrying a maximum of three passengers. In this commentary paper, we express significant concern about the flight safety consequences of the proposed aeromedical requirements of the LPL. We argue that the proposed minimum age, validity period of the medical certificate, and issuance of certificates by general practitioners may increase the flight safety risk. Major revision of the proposed LPL regulation is recommended.

Keywords: aeromedical examination, leisure pilot license, medical requirements, flight safety.
\end{abstract}

$\mathrm{T}$ HE EUROPEAN AVIATION Safety Agency (EASA) is an Agency of the European Union which was set up by a European Council and Parliament regulation in 2002. The Agency is given specific regulatory and executive tasks in the field of civil aviation safety and environmental protection. Tasks of EASA include rulemaking and ensuring uniform implementation of European aviation safety legislation in all Member States.

In their Notice of Proposed Amendment, EASA proposes to introduce a Leisure Pilot License (LPL) in the Basic Regulation with the aim of facilitating access to private flying in Europe (4). The privileges of the holder of a LPL for airplanes - LPL(A) - " are to fly single engine piston aeroplanes with a maximum certificated takeoff mass (MTOW) of $2000 \mathrm{~kg}$ or less, carrying a maximum of 3 passengers, such that there are never more than 4 persons on board the aircraft" (5). This is in marked contrast with more cautious U.S. Federal Aviation Administration (FAA) requirements for the Light Sport Aircraft License which limit the MTOW to $600 \mathrm{~kg}$, the maximum airspeed to $120 \mathrm{kn}$, and the maximum seating capacity to two persons, including the pilot (7). Although more liberal, the EASA proposal shows some similarities with Transport Canada's Pilot Permit Recreational Aeroplanes (PPR), which allows holders to fly in single-engine, non-high-performance aircraft (i.e., velocity to never exceed $<250 \mathrm{kn}$, stall speed with landing configuration $<80$ $\mathrm{kn})$ under visual flight rules carrying no more than one passenger (10).

The average MTOW of recreational aircraft used in Europe is around $1150 \mathrm{~kg}$. As proposed by EASA, any LPL(A) license holder can fly most of the single-engine, four- seat recreational aircraft, including fast and difficultto-control aircraft, like the Cessna 400 (MTOW $1633 \mathrm{~kg}$, max. airspeed $235 \mathrm{kn}$ ). The current European regulations require a Private Pilot License (PPL-Class 2) to fly this category of aircraft.

Our concern concentrates on the following proposed medical requirements of the LPL:

\footnotetext{
- Applicants for the LPL shall be at least $16 \mathrm{yr}$ of age (5).

- LPL medical certificates shall be valid (6):

i) from the initial medical examination until the age of 45 ;

ii) between the age of 45 and 60 , for a period of $60 \mathrm{mo}$;

iii) after the age of 60 , for a period of $24 \mathrm{mo}$.

- LPL medical certificates shall be issued by an Aeromedical Centre, an Authorized Aeromedical Examiner or, if permitted under national law, by a general medical practitioner (6).
}

\section{Concerns}

The age limit of $16 \mathrm{yr}$ and the validity limits do not comply with ICAO standards for PPL Class 2 (8). Practicing below the ICAO standards for private pilots means that holders of LPL licenses will need permission of third countries before flying into, over, or within their territory (4). The validity requirements mean that between the age of 16 and 45, LPL-license holders are free from any medical examination or medical self-declaration. In this context it should be considered that mania, major depression, psychosis, and alcohol or drug dependency are known to have their peak incidence between 16 and $45 \mathrm{yr}$ $(3,2,1)$. Moreover, LPL pilots ages $16-45$ yrs may develop potentially incapacitating diseases, such as HIV/AIDS, urolithiasis, cardiac rhythm disturbances, and impairment of visual capacities in this potential 29-yr aeromedical examination interval.

The proposed LPL validity periods compare unfavorably with the validity periods of Transport Canada's

From the Netherlands Organization for Applied Scientific Research TNO, Soesterberg, Netherlands; Glencairn Medical Centre, Dublin, Ireland; Lufthansa Medical Department, Frankfurt, Germany; and the European Society of Aviation Medicine.

This manuscript was received for review in February 2009. It was accepted for publication in March 2009.

Address reprint requests to: Ries Simons, M.D., Netherlands Organization for Applied Scientific Research TNO, P.O. Box 23, 3769 ZG Soesterberg, Netherlands; ries.simons@tno.nl.

Reprint \& Copyright () by the Aerospace Medical Association, Alexandria, VA.

DOI: $10.3357 /$ ASEM.2522.2009 
PPR, which are set to 60 mo if under $40 \mathrm{yr}$ of age and 24 mo if over $40 \mathrm{yr}$ of age (10) and are considerably liberal for pilots older than $50 \mathrm{yr}$ of age. As a reasonable compromise between epidemiological and flight safety considerations it is recommended to apply the validity periods of EASA's PPL Class 2 also to the LPL: 60 mo until the age of 40, 24 mo between the age of 40 and 50, and 12 mo after the age of 50 (6).

The EASA proposal to allow general practitioners to issue LPL medical certificates resembles the Canadian PPR rules, which require a Class 4 Medical Certificate, which can be issued by any physician licensed to practice in Canada. Although these requirements compare favorably to FAA rules, which only require Light Sport Aircraft License holders to hold a current and valid driver's license as evidence of medical eligibility, it is considered that the EASA proposal may endanger the medical aspects of flight safety. The present European regulations require Class 2 (PPL) medical certificates to be issued by an authorized aeromedical examiner, which ensures sufficient aeromedical expertise, because such aeromedical examiners all hold an aeromedical qualification as described in JAR-FCL-Part 3 Medical (9). The majority of European general practitioners lack aeromedical knowledge, as aviation medicine is not included in any clinical or general practice curriculum. Based on the number of European license holders and the number of general practitioners, it is estimated that the average Western-European general practitioner will, at most, see one pilot per two years seeking aeromedical consultation or examination. Therefore, general practitioners will have no chance to gain sufficient experience in dealing with aeromedical problems.

Of significant concern is that under the proposed LPL regulations the aeromedical "control" on LPL-holders may be completely lost. If a 35-yr-old Leisure Pilot does not want to report his psychosis, the aeromedical community will never be aware of this potential threat. In the very crowded European airspace, a nightmare scenario in which such pilot, accompanied by three passengers, crosses the flight path of a descending B747 might become reality. A collision between these two aircraft usually results in a fatal accident for both aircrafts, which means that such a flying patient can kill hundreds of passengers. Based on these arguments, it is urgently recommended to revise the proposed LPL regulation. We recommend applying the minimum age and validity criteria as proposed by EASA for PPL (Class 2) medical cer- tificates and to permit only Aeromedical Centers and Authorized Aeromedical Examiners to issue medical certificates.

\section{ACKNOWLEDGMENTS}

We thank the members of the Executive Committee of the European Society of Aviation Medicine for supporting the views expressed in this article.

Authors and affiliations: Ries Simons, M.D., Netherlands Organization for Applied Scientific Research TNO, Soesterberg, Netherlands; Declan Maher, M.D., Glencairn Medical Centre, Leopardstown Valley, Dublin, Ireland; Uwe Stueben, Ph.D., M.D., Medical Department, Lufthansa German Airlines, Frankfurt Airport, Germany; and Kevin C. Herbert, M.D., European Society of Aviation Medicine.

\section{REFERENCES}

1. Anthony JC, Echeagaray-Wagner F. Epidemiologic analysis of alcohol and tobacco use. Alcohol Res Health 2000; 24:201-8.

2. Castle DJ, Sham PC, Murray RM. Determinants of age of onset in psychosis. Schizophrenia Research 1998; 29:24-5(2).

3. Eaton WW, Anthony JC, Gallo J, Cai G, Tien A, et al. Natural history of Diagnostic Interview Schedule/DSM-IV major depression. The Baltimore Epidemiologic Catchment Area follow-up. Arch Gen Psychiatry 1997; 54:993-9.

4. European Aviation Safety Agency. Notice of Proposed Amendment (NPA) No 200817A. “Implementing Rules for Pilot Licensing." A. Explanatory Note and Appendices. European Aviation Safety Agency, 3 June 2008. Retrieved 1 February 2009 from http:/ / www.easa.eu.int/ws_prod/r/doc/NPA/NPA \%20 2008-17a.pdf.

5. European Aviation Safety Agency. Notice of Proposed Amendment (NPA) No 200817B. "Implementing Rules for Pilot Licensing." B. Part FCL. European Aviation Safety Agency, 3 June 2008. Retrieved 1 February 2009 from http:/ /www.easa.eu.int/ ws_prod/r/doc/NPA/NPA\%202008-17b.pdf.

6. European Aviation Safety Agency. Notice of Proposed Amendment (NPA) No 200817C. "Implementing Rules for Pilot Licensing." C. Part-Medical. European Aviation Safety Agency, 3 June 2008. Retrieved 1 February 2009 from http:/ / www.easa.eu.int/ ws_prod/r/doc/NPA/NPA\%202008-17c.pdf.

7. Federal Aviation Administration. 14 CFR Parts 1, 21, et al. Certification of Aircraft and Airmen for the Operation of Light-Sport Aircraft; Final Rule. Department of Transportation, Federal Aviation Administration. Federal Register Vol. 69, No. 143, 2004. Rules and Regulations. Retrieved 1 February 2009 from http:/ / edocket.access.gpo.gov/2004/pdf/04-17081.pdf.

8. International Civil Aviation Organization. Annex 1 to the Convention on International Civil Aviation - Personnel Licensing, Ninth Edition, July 2001. Order No. AN 1. Montreal, Canada: International Civil Aviation Organization - Air Navigation Bureau (ANB); 2001.

9. Joint Aviation Authorities. JAR-FCL 3 - Flight Crew Licensing (Medical) 2006. Joint Aviation Authorities, Hoofddorp, Netherlands. Retrieved 1 February 2009 from http:/ / www.jaa. $\mathrm{nl} /$ publications/jars/606984.pdf.

10. Transport Canada. Part IV - Personnel Licensing and Training. Subpart 1- Flight Crew Permits, Licences and Ratings. Retrieved 16 March 2009 from http://www.tc.gc.ca/CivilAviation/ Regserv/Affairs/cars/Part4/Subpart1.htm. 